Crop Breeding and Applied Biotechnology 15: 154-161, 2015

Brazilian Society of Plant Breeding. Printed in Brazil

\title{
ARTICLE
}

http://dx.doi.org/10.1590/1984-70332015v15n3a27

\section{Combining ability and heterosis of relevant fruit traits of tomato genotypes for industrial processing}

Alex Sandro Torre Figueiredo ${ }^{1 *}$, Juliano Tadeu Vilela de Resende ${ }^{2}$, Marcos Ventura Faria ${ }^{2}$, Juliana Tauffer de Paula ${ }^{3}$, Kélin Schwarz ${ }^{2}$ and Daniel Suek Zanin ${ }^{2}$

Received 03 August 2014

Accepted 23 January 2015

\begin{abstract}
The objective was to estimate the combining ability of lines and heterosis in industrial tomato genotypes for the identification of those with good potential for breeding programs. Ten lines of industrial tomato, 45 hybrids derived from a complete diallel and two commercial check cultivars were evaluated. The combining ability of tomato lines and heterosis of hybrid combinations for fruitquality related traits were estimated. Non-additive effects predominated in the genetic control of all traits. The parent lines $R V T D-04$, RVTD-10 and RVTD-08 had an exceptionally high presence of favorable alleles for most traits. High genetic divergence between the parents was observed, contributing positively to significant heterosis values. The above lines can be used in breeding programs to develop tomato hybrids with high performance for characteristics related to industrial processing.
\end{abstract}

Key words: Solanum lycopersicum, diallel, genetic divergence.

\section{INTRODUCTION}

Tomato (Solanum lycopersicum L. Mill) is the second most important vegetable species in the world and is grown practically throughout Brazil. In 2013, the country produced 3.86 million tons of tomato fruits, a third of which was destined for industrial processing, ranking fifth among the world's tomato--producing countries (IBGE 2014).

One of the difficulties of industrial tomato production is the low quality of the raw material coming from the field, which can influence the quality of processed pulp directly (Boiteux et al. 2012). The quality of fruit for processing can be characterized by a number of physico-chemical properties, e.g., soluble solids content, titratable acidity, soluble solid- titratable acidity ratio, vitamin $\mathrm{C}$ content, and fruit color (related to the lycopene content). However, the nature of part of the phenotypic variation observed for tomato-fruit quality related traits is genetic, enabling the generation of variability and the selection of superior genotypes, contributing to improve the quality of raw material to be processed (Melo et al. 2009, Boiteux et al. 2012).

Throughout evolution, domestication and dispersion to different parts of the world, the genetic base of tomato was strongly narrowed, resulting in the loss of alleles of interest for breeding, including of fruit quality. Thus, no intrapopulational breeding strategies have been used in current tomato breeding programs, due to the low resulting genetic gain (Amaral Júnior et al. 1999, Souza et al. 2012).

A genotype promising for a particular purpose will not always transfer its favorable alleles to its progenies successfully. Diallel crosses are used to estimate the allele transfer capacity, which are genetic designs widely exploited in breeding programs for numerous species and purposes, including for tomato (Maluf 2001). Diallels are genetic designs that partition the sum of square of treatments in combining ability effects of the parents, providing researchers with important information, e.g., about the predominant gene action in trait expression, heterosis of hybrid combinations and also which breeding strategy is the most indicated (Cruz et al. 2012).

The objective of this study was to estimate the combining ability and heterosis of tomato genotypes with a view to finding superior experimental hybrids and choose potential genotypes for breeding programs targeting improved fruit traits for industrial processing.

\footnotetext{
${ }^{1}$ Universidade Estadual de Maringá (UEM), 87.020-270, Maringá, PR, Brazil. *E-mail: alexstfigueiredo@gmail.com

${ }^{2}$ Universidade Estadual do Centro Oeste (UNICENTRO), Campus CEDETEG, 85.040-080, Guarapuava, PR, Brazil

${ }^{3}$ Escola Superior de Agricultura Luiz de Queiroz (ESALQ), 13.418-900, Piracicaba, SP, Brazil
} 


\section{MATERIAL AND METHODS}

This field experiment was conducted in the experimental area of a center for vegetable research (Núcleo de Pesquisa em Hortaliças - NUPH) of the Universidade Estadual Centro Oeste (UNICENTRO) in Guarapuava - PR (lat 25 22' S, long $51^{\circ} 29^{\prime} \mathrm{W}$, alt $1105 \mathrm{~m}$ asl) on a Latossolo Bruno (Clayey Oxisol), from September 2011 to March 2012.

The experiment consisted of a complete diallel of 10 industrial tomato lines selected in NUPH. A total of 57 genotypes with industrial suitability were evaluated (45 single diallel crosses, 10 parent lines and 2 commercial hybrids, i.e., AP-529 and Tinto), in a randomized block design with three replications. Each experimental unit consisted of two neighboring plant rows spaced $1.20 \mathrm{~m}$ apart, containing eight plants each, spaced $0.35 \mathrm{~m}$ apart. Two plants on either end of the plots were considered border, with a total evaluated area of $5.46 \mathrm{~m}^{2}$.

The genotypes were sown in 200-cell trays with subsequent planting of seedlings in the field, after 30 days. During the growing season, fertilization was applied three times (at planting, flowering and full fruiting), based on chemical analysis of soil and nutrient requirements of the crop. Sprinkler irrigation was applied when needed by the plants. Pests and diseases were controlled by weekly applications of insecticides (acephate, triflumuron and thiamethoxam) and fungicides (copper oxychloride, Metalaxyl-M, Mancozeb, and Chlorothalonil), dosed as recommended for the crop.

Five samplings were performed throughout the experiment. At the third sampling, 15 fruits per plot were harvested $(80 \%$ of the fruit with deep red color) with uniform appearance, health and size. At the Laboratory of Plant Physiology of UNICENTRO, the fruits were washed in running water and ground, in preparation for the quality analysis. Each assay was performed in triplicate, however the statistical analysis was based on the mean value per plot. We evaluated the following traits: soluble solids (SS: ${ }^{\circ}$ Brix); titratable acidity (TA: g of citric acid $100 \mathrm{~g} \mathrm{pulp}^{-1}$ ) (Adolfo Lutz, 2005); ratio (ratio between soluble solids/ titratable acidity); vitamin C content (VC: $\mathrm{mg}$ of ascorbic acid $100 \mathrm{~g} \mathrm{pulp}^{-1}$ ) (Benassi and Antunes 1988); reducing sugars (RS) (Brasil 2005); lycopene (IL: lycopene $\mu$ g pulp $^{-1}$ ) (Rodriguez Amaya 2001) and phenolic compounds (PhC: mg equivalent to $100 \mathrm{~g}$ gallic acid pulp $^{-1}$ ). The phenotypic values of postharvest variables evaluated in the experiment in inbred lines and commercial hybrids are detailed in Table 1.

After confirming the normality of errors and homogeneity of variances by Lilliefors and Bartlett tests $(\mathrm{P}<0.05)$, respectively, analysis of variance was performed for a randomized block design, consisting of 57 treatments in 3 replications and with 112 degrees of freedom (DF) of the error. In the case of significance of $\mathrm{F}$ for treatment, the 56 degrees of freedom of treatment were partitioned in effects of lines (9 DF), experimental hybrids (44 DF), commercial hybrids (1 DF), and mean contrasts between "lines versus hybrids" (1 DF) and "experimental hybrids vs commercial hybrids" (1 DF) (Cruz et al. 2012).

For the diallel analysis, only data of the 10 parents and 45 experimental hybrids were considered, totaling 108 degree of freedon of error in diallel variance analysis. Thus, the $54 \mathrm{DF}$ treatment were deployed by diallel analysis of estimates for general $\left(\hat{g}_{i}\right)$ and specific combining ability $\left(\hat{s}_{i i}\right.$ and $\hat{s}_{i j}$ ), according to Method II (parents and $\mathrm{F}_{1}$ hybrids), model 1 (fixed effects for genotypes), according to Griffing (1956). The statistical model used was $\mathrm{Y}_{i j}=m+g_{i}+g_{j}+$ $s_{i j}+e_{i j}$ where $\mathrm{Y}_{i j}$ is the value of the hybrid combination $(\mathrm{i} \neq$ $\mathrm{j}) ; m$ is the general mean; $g_{i}$ and $g_{j}$ are estimates of general

Table 1. Mean values of soluble solids (SS, ${ }^{\circ}$ Brix), titratable acidity (TA, g citric acid $100 \mathrm{~g}^{-1}$ fresh fruit), SS/TA ratio, vitamin C content (VC, mg of ascorbic acid $100 \mathrm{~g}^{-1}$ pulp), reducing sugars (RS, \%), lycopene (LI, $\mu \mathrm{g}$ lycopene $\mathrm{g}^{-1}$ fresh fruit) and phenolic compounds (PhC, $\mathrm{g}^{-1}$ pulp) observed in 10 lines of industrial tomato and in the two commercial check cultivars in an experiment in the center-south region of Paraná

\begin{tabular}{lccccccc}
\hline Genotype & SS & TA & Ratio & VC & RS & LI & PhC \\
\hline RVTD-01 & 4.07 & 0.37 & 14.07 & 13.02 & 2.37 & 31.16 & 37.55 \\
RVTD-02 & 4.23 & 0.31 & 9.30 & 10.37 & 2.48 & 59.14 \\
RVTD-03 & 4.09 & 0.45 & 14.30 & 8.22 & 1.95 & 46.72 \\
RVTD-04 & 4.10 & 0.35 & 13.04 & 11.50 & 2.33 & 42.02 & 33.31 \\
RVTD-05 & 4.17 & 0.34 & 12.71 & 20.21 & 2.10 & 47.69 \\
RVTD-06 & 4.03 & 0.40 & 11.12 & 17.84 & 1.71 & 40.91 \\
RVTD-07 & 3.83 & 0.41 & 9.55 & 11.93 & 1.88 & 29.68 & 36.23 \\
RVTD-08 & 4.67 & 0.28 & 11.57 & 14.80 & 1.77 & 50.43 \\
RVTD-09 & 4.27 & 0.36 & 11.66 & 17.25 & 2.28 & 41.99 \\
RVTD-10 & 4.70 & 0.41 & 13.32 & 16.11 & 2.98 & 34.41 \\
\hline AP-529 & 4.10 & 0.29 & 9.79 & 12.78 & 2.60 & 38.04 & 36.95 \\
Tinto & 3.73 & 0.27 & 11.69 & 11.51 & 2.08 & 26.87 \\
\hline
\end{tabular}


combining ability of the $\mathrm{i}^{\text {th }}$ and $\mathrm{j}^{\text {th }}$ parent, respectively; $s_{i j}$ is the estimated specific combining ability between parents $i$ and $\mathrm{j}$; and $e_{i j}$ is the mean experimental error. The analyses were performed using statistical software Genes (Cruz 2013).

Heterosis in hybrid combinations was estimated (in percentage) for all traits. The heterosis estimates were obtained by the expression $H_{(\%)}=\left(\frac{F_{1}-\left(\frac{P_{1}+P_{2}}{2}\right)}{F_{1}}\right) x 100$ , where $\mathrm{H}_{(\%)}$ is the heterosis in percentage; $F_{1}$ : mean of hybrid combination $F_{1}$; and $P_{1}$ and $P_{2}$ are the means of the respective parents.

\section{RESULTS AND DISCUSSION}

The coefficients of variation were obtained with high experimental precision and the quality properties of industrial tomato fruits were little influenced by uncontrollable environmental variations. The values ranged from $0.80 \%$ to $3.95 \%$ for the characteristics phenolic compounds $(\mathrm{PhC})$ and ratio, respectively (Table 2), and were considered low, according to the classification proposed by Gomes (1990).

There were significant differences $(\mathrm{P}<0.05)$ between treatments for the seven fruit-quality related traits (Table 2 ), due to genetic differences between genotypes and high experimental precision. This indicates the existence of genetic variability between the parent lines, experimental hybrids and commercial hybrids for all evaluated properties, making the selection of the best genotypes possible. The recombination of pre-existing genetic variability by means of diallel crosses resulted in the formation of different experimental hybrids for the evaluated traits, allowing selection and finally recommendation of the best hybrids in the breeding program aimed at improving fruit quality properties (Melo et al. 2009, Santos et al. 2011, Souza et al. 2012).

The contrast 'lines versus other genotypes' allowed conclusions about the mean heterosis observed in hybrid combinations, reflecting the superiority of hybrids from the mean of the inbred lines. For this contrast, all variables related to fruit quality were influenced significantly, indicating the superiority of means of the hybrids compared to those of lines (Table 2).

The contrast of experimental with commercial hybrids shows possible mean differences between the hybrids obtained by diallel crosses and commercial hybrids. The

Table 2. Summary of analysis of variance of the trial and the diallel, with partitioning of the degrees of freedom of treatment (genotypes) in isolated effects and contrasts for traits related to tomato fruit quality for industrial processing

\begin{tabular}{|c|c|c|c|c|c|c|c|c|}
\hline \multicolumn{9}{|c|}{ ANOVA trial } \\
\hline \multirow{2}{*}{ SV } & \multirow{2}{*}{ df } & \multicolumn{7}{|c|}{ Mean Square } \\
\hline & & SS & TA & Ratio & $\mathrm{VC}$ & RS & LI & $\mathrm{PhC}$ \\
\hline Block & 2 & 0.0122 & 0.0001 & 0.186 & 0.198 & 0.003 & 0.055 & 0.049 \\
\hline Genotype & $(56)$ & $0.3230^{*}$ & $0.0072^{*}$ & $7.35^{*}$ & $28.91^{*}$ & $0.464^{*}$ & $225.80^{*}$ & $13.24^{*}$ \\
\hline Line & 9 & $0.2239^{*}$ & $0.0076^{*}$ & $9.07^{*}$ & $42.28^{*}$ & $0.445^{*}$ & $176.65^{*}$ & $11.91^{*}$ \\
\hline Exp. hybrid (EH) & 44 & $0.3502^{*}$ & $0.0066^{*}$ & $4.87^{*}$ & $26.60^{*}$ & $0.484^{*}$ & $225.24^{*}$ & $12.70^{*}$ \\
\hline $\mathrm{EH}$ vs $\mathrm{CH}$ & 1 & $0.3019^{*}$ & $0.0273^{*}$ & $10.30^{*}$ & $49.13^{*}$ & $0.223^{*}$ & $1006.9^{*}$ & $56.28^{*}$ \\
\hline Error & 112 & 0.0067 & 0.0001 & 0.22 & 0.305 & 0.003 & 0.137 & 0.087 \\
\hline CV $(\%)$ & - & 1.97 & 2.85 & 3.95 & 3.73 & 2.37 & 0.87 & 0.80 \\
\hline Mean & - & 4.15 & 0.35 & 12.03 & 0.39 & 2.15 & 42.46 & 36.41 \\
\hline \multicolumn{9}{|c|}{ ANOVA Diallel } \\
\hline$\hat{\mathrm{g}}_{\mathrm{i}}$ & 9 & $0.35^{*}$ & $0.0040^{*}$ & $3.95^{*}$ & $34.70^{*}$ & $0.51^{*}$ & $151.09^{*}$ & $33.80^{*}$ \\
\hline$\hat{\mathrm{s}}_{\mathrm{ij}}$ & 44 & $0.31^{*}$ & $0.0074^{*}$ & $8.01^{*}$ & $28.01^{*}$ & $0.45^{*}$ & $226.45^{*}$ & $8.22^{*}$ \\
\hline Error & 108 & 0.007 & 0.00009 & & 0.3148 & 0.0026 & 0.1415 & 0.0828 \\
\hline Quadratic component & & $\mathrm{SS}$ & TA & Ratio & $\mathrm{VC}$ & RS & LI & $\mathrm{PhC}$ \\
\hline$\Phi \hat{\mathrm{g}}_{\mathrm{i}}$ & - & 0.0095 & 0.00011 & 0.10 & 0.9552 & 0.0143 & 4.1931 & 0.9367 \\
\hline$\Phi \hat{\mathrm{s}}_{\mathrm{ij}}$ & - & 0.1041 & 0.00240 & 2.59 & 9.2328 & 0.1524 & 75.4379 & 2.7137 \\
\hline
\end{tabular}

"significant and non-significant by the $\mathrm{F}$ test $(\mathrm{P}<0.05)$.

SS: soluble solids ( ${ }^{\circ}$ Brix); TA: titratable acidity ( $\mathrm{g}$ citric acid $100 \mathrm{~g}^{-1}$ fresh fruit); Ratio; VC: vitamin C (mg ascorbic acid $100 \mathrm{~g}^{-1}$ pulp); RS: reducing sugars (\%); LI: lycopene ( $\mu \mathrm{g}$ lycopene $\mathrm{g}^{-1}$ fresh fruit); PhC: phenolic compounds $\left(\mathrm{g}^{-1} \mathrm{pulp}\right)$. 
significance of this contrast $(\mathrm{P}<0.05)$ and the positive estimates indicate that the diallel crosses allowed the establishment of new tomato hybrids with a better mean performance than that of the commercial hybrids used as controls, for all fruit-quality related traits (Table 2). Literature results show that methods that provide the recombination of genetic variability obtained greater advances in tomato breeding than intrapopulational strategies, due to the narrow genetic base of the crop, confirming the results of this study (Amaral Júnior et al. 1997, Souza et al. 2012).

The general combining ability (GCA) shows the behavior of a given parent prior to the crosses in which it participated, reflecting the action of additive gene effects. High and absolute values of the GCA estimates $\left(\hat{g}_{i}\right)$ are detected in clones whose frequency of favorable alleles is higher or lower than the mean frequency of favorable alleles in all other parents of the diallel. On the other hand, the specific combining ability (SCA) is a hybrid deviation from the expected $\hat{g}_{i}$ based on the parents and reflects the action of genes with non-additive effect. However, the best hybrid combinations for breeding are those with high SCA estimates and a favorable GCA estimate in at least one parent (Cruz et al. 2012).

All seven fruit-quality related characteristics were influenced significantly $(\mathrm{P}<0.05)$ by the effects of $\hat{g}_{i}$ and $\hat{s}_{i j}$, indicating that genes with additive as well as non-additive effects were relevant in the expression of these traits, corroborating with other literature results about tomato breeding (Dhaliwal et al. 1999, Shende et al. 2012, Souza et al. 2012).

The significance of $\hat{g}_{i}$ estimates for all traits indicates the presence of parents with higher frequency of alleles favorable for the improvement of fruit quality related traits for industrial processing and genetic gain is possible by choosing the right parents. On the other hand, the significance of $\hat{s}_{i j}$ estimates indicates that among the diallel-derived hybrids, some deviations from the expected, based on the $\hat{g}_{i}$ of the parents, were significant, showing a considerable complementarity between the lines for loci with non-additive effects (Vencovsky and Barriga 1992).

The relationship between the quadratic components of $\hat{g}_{i}$ and $\hat{s}_{i j}$ indicate which gene effect is predominant in trait expression. When $\hat{g}_{i}$ is greater than $\hat{s}_{i j}$, the additive gene effects are prevalent in trait expression and intrapopulational breeding strategies should be chosen. However, when $\hat{s}_{i j}$ exceeds $\hat{g}_{i}$, non-additive gene effects are predominant and interpopulational breeding strategies are ideal (Cruz et al. 2012).
The estimates of the quadratic component of $\hat{s}_{i j}$ of all traits were relatively higher than those of $\hat{g}_{i}$ (Table 2) and the interpopulational breeding strategies are the most recommended for the improvement of these variables (Amaral Júnior et al. 1999, Garg et al. 2008, Shende et al. 2012, Souza et al. 2012, Saleem et al. 2013).

Estimates of the effects of general combining ability $\left(\hat{g}_{i}\right)$ have oriented breeders in the choice of the best parents for intrapopulational breeding programs. However, along with the $\hat{g}_{i}$ estimates, the standard deviation of the contrasts of the effects must be simultaneously considered. Therefore, in this study the parents whose $\hat{g}_{i}$ estimates exceeded the standard deviation of the contrasts of the effects twice, ensuring a difference between $i$ and $j$ parents, were considered superior (Cruz et al. 2012).

For industrial tomato, the higher the SS content, the lower will be energy expenditure for pulp concentration, facilitating industrial operations; SS levels above $5.0^{\circ}$ Brix are ideal for the processing industry. The variation range of $\hat{g}_{i}$ values for SS was 13 times the standard deviation of the difference between two lines $\left(S D_{\hat{g} i-\hat{g} j}\right)$. However, only the parents RVTD-08 and RVTD-10 stood out for the frequency of favorable alleles with additive effect for breeding of total SS content, promoting a mean increase of 0.14 and 0.15 ${ }^{\circ}$ Brix, respectively, in crosses (Table 3 ).

Thus, the tomato processing industry has promoted the breeding of hybrids that combine ease in fruit processing with excellent nutritional quality (Boiteux et al. 2012). One of the characteristics inherent to the raw material and relevant for processing is titratable acidity (TA), since the higher the citric acid content in the pulp, the lower is microbial proliferation. Other nutraceutically important traits are lycopene content (LI) and phenolic compounds (PhC), which together act in free-radical protection of the body. Thus, there is a range of variation of $15.90,70.56$ and 51.80 times the standard deviation of the difference between two lines for $\hat{g}_{i}$ estimates associated with the variables TA, LI and FC, respectively. RVTD-04 was the only parent with detectable $\hat{\mathrm{g}}_{\mathrm{i}}$ estimates for the traits TA $(0.014 \mathrm{~g}$ citric acid $100 \mathrm{~g}^{-1}$ fresh fruit), LI (3.06 $\mu \mathrm{g}$ lycopene $\mathrm{g}^{-1}$ fresh fruit) and $\mathrm{PhC}$ (1.63 mg $100 \mathrm{~g}^{-1}$ pulp), in response to the higher frequency of favorable alleles (Table 3 ).

The SS/TA ratio expresses the general relationship between sugar and acid in fruit. For tomato, the optimum ratio should be above 10 , to ensure a mild flavor of the fruit. The range of variation of $\hat{g}_{i}$ values for the ratio was 8.27 times the standard deviation of the difference between two parents. Consequently, the best parents were RVTD-04 (0.38), RVTD-03 (0.37), RVTD-10 (0.35), and RVTD-09 
(0.16), for inducing an increase of this ratio in hybrids in which they were parents. It is worth emphasizing the genetic merit of parent RVTD-04, in view of its greater frequency of favorable alleles and with additive effect on the improvement of TA, LI and PhC than of the other parents (Table 3).

The range of variation in $\hat{g}_{i}$ values observed for the RS content was 32 times the standard deviation of the difference between the $\hat{g}_{i}$ estimates of both parents. Therefore, for this experiment, the line with the highest frequency of favorable alleles for increased levels of reducing sugars in tomato fruit was RVTD-03, increasing the sugar content by $0.23 \%$ in crosses (Table 3).

Vitamin C (VC), represented by the ascorbic acid content, has a considerable antioxidant effect, and tomato is one of the vegetables with highest contents of this natural antioxidant. The $\hat{g}_{i}$ estimates had a range of 25 times the standard deviation of the difference between two parents. Line RVTD-05 was the only parent with very high $\hat{g}_{i}$ estimates for the increase of VC content in tomato fruit (Table 3 ).

For breeding, the best hybrid combination is one with a high $\hat{s}_{i j}$ estimate and at least one of the parents with a high $\hat{g}_{i}$ estimate (Cruz et al. 2012). For the SS content, the amplitude of variation of $\hat{s}_{i j}$ estimates was 17.81 times the standard deviation $\left(S D_{\hat{s} i j-\hat{s i k}}\right)$, especially in the hybrid combinations RVTD-07 x RVTD-10 (0.47 ${ }^{\circ}$ Brix), RVTD-02 x RVTD08 (0.44 ${ }^{\circ}$ Brix), RVTD-05 x RVTD-10 (0.35 ${ }^{\circ}$ Brix) and RVTD-06 x RVTD-08 ( $0.35^{\circ}$ Brix $)$ as the best of the diallel, for having concomitantly the highest $\hat{s}_{i j}$ estimates and lines RVTD-08 and RVTD-10 as parents (Table 4).

Line RVTD-04 was the best parent for the traits TA, LI and $\mathrm{PhC}$, which, along with the high $\hat{s}_{i j}$ estimates, made it a reference for the choice of the best hybrids. Therefore, the range of variation of the $\hat{s}_{i j}$ estimates for TA was 40 times the standard deviation and the best hybrid combinations were RVTD-04 x RVTD-05 and RVTD-04 x RVTD-09. For LI contents, the range of variation of the $\hat{s}_{i j}$ estimates was 113.4 times the standard deviation and the best hybrids for breeding of this trait were RVTD-04 x RVTD09, RVTD 04-x-06 RVTD, RVTD- $01 \times$ RVTD-04 and RVTD02 x RVTD-04. The amplitude of variation for the PhC content was 32.75 times the standard deviation, making hybrids RVTD-04 x RVTD-06, RVD-04 x RVTD-10 and RVTD-04 $x$ RVTD-07 the most recommendable for breeding (Table 4).

For the SS/TA ratio, the range of variation of the $\hat{s}_{i j}$ estimates was 18.51 times the standard deviation; the hybrid combinations RVTD-09 x RVTD-10 (3.91), RVTD-04 x RVTD-06 (1.55), RVTD-02 x RVTD-04 (1.53), RVTD-03 $x$ RVTD-04 (1.46), and RVTD03 x RVTD-05 stood out with high $\hat{s}_{i j}$ estimates and the lines RVTD-04, RVTD-03 and RVTD-10 as parents (Table 4). For the VC content, the amplitude of variation of the $\hat{s}_{i j}$ estimates was approximately 28 times the standard deviation observed for this trait, so that only two hybrid combinations (RVTD-01 x RVTD-05 with $3.08 \mathrm{mg}$ ascorbic acid $100 \mathrm{~g}^{-1}$ pulp and RVTD-03 x RVTD05 with $2.18 \mathrm{mg}$ ascorbic acid $100 \mathrm{~g}^{-1}$ pulp) had excellent $\mathrm{VC}$ contents, with positive $\hat{s}_{i j}$ values, and at the same time, parent RVTD-05, which had the highest $\hat{g}_{i}$ estimate of the diallel for this trait (Table 4). For the RS content, the choice criterion of the best hybrid combinations for breeding is the presence of parent RVTD-03 along with high $\hat{s}_{i j}$ estimates, which indicated the hybrid combinations RVTD03 x RVTD09 (0.75\%), RVTD-01 x RVTD-03 (0.68\%) and RVTD-03 $x$ RVTD-07 $(0.56 \%)$ (range of 32.75 times the standard deviation) (Table 4).

Table 3. Estimates of general combining ability $\left(\hat{g}_{i}\right)$ and specific combining ability of each tomato line with itself $\left(\hat{s}_{i j}\right)$ for traits related to tomato fruit quality for industrial processing

\begin{tabular}{|c|c|c|c|c|c|c|c|c|c|c|c|c|c|c|}
\hline \multirow{2}{*}{ Parent } & \multicolumn{2}{|c|}{ SS } & \multicolumn{2}{|c|}{ TA } & \multicolumn{2}{|c|}{ Ratio } & \multicolumn{2}{|c|}{$\mathrm{VC}$} & \multicolumn{2}{|c|}{ RS } & \multicolumn{2}{|c|}{ LI } & \multicolumn{2}{|c|}{$\mathrm{PhC}$} \\
\hline & $\hat{g}_{i}$ & $\hat{s}_{i j}$ & $\hat{g}_{i}$ & $\hat{s}_{i j}$ & $\hat{g}_{i}$ & $\hat{s}_{i j}$ & $\hat{g}_{i}$ & $\hat{s}_{i j}$ & $\hat{g}_{i}$ & $\hat{s}_{i j}$ & $\hat{g}_{i}$ & $\hat{s}_{i j}$ & $\hat{g}_{i}$ & $\hat{s}_{i j}$ \\
\hline RVT-01 & -0.04 & 0.004 & 0.007 & 0.002 & 0.13 & 1.72 & 0.89 & -3.66 & -0.02 & 0.28 & -0.17 & -1.43 & 0.77 & -0.31 \\
\hline RVT-02 & 0.02 & 0.02 & -0.012 & -0.01 & -0.53 & -1.70 & 0.29 & -5.10 & 0.08 & 0.15 & 2.24 & 11.7 & -1.84 & 0.95 \\
\hline RVT-03 & 0.02 & -0.11 & 0.009 & 0.07 & 0.37 & 1.48 & -1.71 & -3.24 & 0.23 & -0.67 & -2.12 & 8.03 & -1.06 & -0.86 \\
\hline RVT-04 & -0.10 & 0.16 & 0.014 & -0.03 & 0.38 & 0.19 & -0.62 & -2.15 & -0.15 & 0.48 & 3.06 & -7.05 & 1.63 & -1.49 \\
\hline RVT-05 & 0.06 & -0.12 & 0.001 & -0.01 & -0.12 & 0.89 & 1.60 & 2.09 & 0.02 & -0.09 & -0.72 & 6.20 & 0.09 & -0.25 \\
\hline RVT-08 & 0.14 & 0.22 & -0.003 & -0.06 & -0.31 & 0.12 & -0.91 & 1.71 & -0.04 & -0.28 & 1.54 & 4.40 & -0.50 & -0.87 \\
\hline RVT-09 & -0.08 & 0.27 & -0.021 & 0.04 & 0.16 & -0.73 & 0.75 & 0.84 & -0.05 & 0.24 & -0.98 & 1.02 & 0.10 & 1.52 \\
\hline RVT-10 & 0.15 & 0.23 & 0.001 & 0.05 & 0.35 & 0.53 & -0.53 & 2.27 & 0.07 & 0.67 & -3.15 & 4.64 & -0.03 & 0.70 \\
\hline $\mathrm{SD}_{(\hat{g} i)}$ & 0.013 & - & 0.0015 & - & 0.07 & - & 0.088 & - & 0.008 & - & 0.059 & - & 0.045 & - \\
\hline $\mathrm{SD}_{(\hat{\alpha} i \hat{g} i)}$ & 0.02 & - & 0.0022 & - & 0.11 & - & 0.132 & - & 0.012 & - & 0.088 & - & 0.067 & - \\
\hline
\end{tabular}

SS: soluble solids ( ${ }^{\circ}$ Brix); TA: titratable acidity (g citric acid $100 \mathrm{~g}^{-1}$ fresh fruit); Ratio; VC: vitamin C ( $\mathrm{mg}$ ascorbic acid $100 \mathrm{~g}^{-1}$ pulp); RS: reducing sugars (\%); LI: lycopene ( $\mu \mathrm{g}$ lycopene $\mathrm{g}^{-1}$ fresh fruit); PhC: phenolic compounds $\left(\mathrm{g}^{-1}\right.$ pulp). 
Combining ability and heterosis of relevant fruit traits of tomato genotypes for industrial processing

Table 4. Estimates of specific combining ability $\left(\hat{s}_{i j}\right)$ and percentage of parent heterosis $\left(H_{\%}\right)$ of tomato hybrid combinations, for fruit-quality related traits for industrial processing

\begin{tabular}{|c|c|c|c|c|c|c|c|c|c|c|c|c|c|c|}
\hline \multirow{2}{*}{ Genotype } & \multicolumn{2}{|c|}{ SS } & \multicolumn{2}{|c|}{ TA } & \multicolumn{2}{|c|}{ Ratio } & \multicolumn{2}{|c|}{$\mathrm{VC}$} & \multicolumn{2}{|c|}{ RS } & \multicolumn{2}{|c|}{ LI } & \multicolumn{2}{|c|}{$\mathrm{PhC}$} \\
\hline & $\hat{s}_{i j}$ & $H_{\%}$ & $\hat{s}_{i j}$ & $H_{\%}$ & $\hat{s}_{i j}$ & $H_{\%}$ & $\hat{s}_{i j}$ & $H_{\%}$ & $\hat{s}_{i j}$ & $H_{\%}$ & $\hat{s}_{i j}$ & $H_{\%}$ & $\hat{s}_{i j}$ & $H_{\%}$ \\
\hline $01 \times 02$ & -0.13 & -3.6 & 0.04 & 14.2 & 0.39 & 3.32 & 2.99 & 63 & -0.31 & -22.1 & -0.07 & -10.4 & 1.82 & 4.22 \\
\hline $01 \times 03$ & 0.03 & 2.04 & -0.05 & -23.4 & -0.42 & -14.3 & 1.67 & 48.3 & 0.68 & 40.8 & -6.16 & -21.5 & 3.10 & 10.4 \\
\hline $01 \times 05$ & 0.55 & 14.9 & 0.04 & 13.6 & -2.92 & -31.6 & 3.08 & 23.2 & -0.26 & -15.8 & -5.16 & -17 & -1.31 & -2.8 \\
\hline $01 \times 06$ & -0.12 & -2.8 & 0.02 & -0.12 & 0.65 & 1.65 & -4.70 & -25.4 & -0.30 & -19.3 & 6.18 & 15.8 & 2.31 & 12.4 \\
\hline $01 \times 09$ & -0.09 & -5.6 & -0.06 & -24.3 & -2.94 & -26.7 & -0.81 & 3.94 & -0.34 & -26.2 & 6.03 & 15 & -1.23 & -4.9 \\
\hline $01 \times 10$ & -0.53 & -14.8 & -0.04 & -17.4 & 0.45 & -4.94 & 4.99 & 39 & -0.27 & -28.3 & 4.05 & 5.94 & 0.16 & -0.06 \\
\hline $02 \times 03$ & 0.29 & 8.0 & 0.002 & -7.57 & -1.18 & -9.1 & 4.11 & 89.1 & -0.24 & 0.59 & -14.5 & -46.1 & -0.89 & 2.81 \\
\hline $02 \times 04$ & -0.37 & -11.2 & -0.07 & -15.7 & 1.53 & 20.5 & 3.06 & 61.2 & -0.10 & -17.9 & 5.72 & 6.7 & -0.61 & -0.94 \\
\hline $02 \times 05$ & -0.48 & -10.3 & 0.06 & -19.9 & 1.21 & 14.72 & -2.08 & -3.76 & -0.25 & -12.6 & -6.91 & -29.7 & -1.32 & -4.8 \\
\hline $02 \times 09$ & -0.20 & -8.2 & -0.01 & -0.44 & 2.25 & 33.17 & 0.45 & 18.7 & -0.17 & -15.8 & -3.26 & -19.0 & 1.17 & -0.17 \\
\hline $02 \times 10$ & -0.40 & -11.9 & -0.01 & -9.9 & -0.90 & -2.81 & -0.80 & 4.64 & -0.39 & -29.7 & -15.5 & -47.2 & -0.63 & -4.13 \\
\hline $03 \times 04$ & -0.24 & -6.5 & -0.04 & -17.2 & 1.46 & 4.58 & 4.87 & 76.8 & -0.16 & -8.13 & -7.86 & -18.8 & -1.67 & -1.37 \\
\hline $03 \times 05$ & -0.25 & -3.2 & -0.04 & -18.6 & 1.23 & 0.33 & 2.18 & 19.4 & -0.05 & 16.3 & 8.20 & 2.3 & -0.43 & 0.35 \\
\hline $03 \times 06$ & -0.26 & -4.9 & -0.08 & -35.7 & -0.71 & -8.20 & 1.52 & 15.0 & 0.02 & 22.5 & -0.65 & -11.5 & 0.94 & 9.97 \\
\hline $03 \times 07$ & -0.20 & -2.5 & -0.06 & -15.6 & 0.22 & 3.17 & -2.58 & 3.32 & 0.56 & 56.2 & 17.4 & 56.9 & 2.72 & 9.32 \\
\hline $03 \times 08$ & 0.30 & 5.7 & 0.05 & 12.5 & 0.81 & 0.11 & 0.03 & 6.7 & -0.03 & 23.9 & -4.55 & -22.1 & 0.57 & 4.26 \\
\hline $03 \times 09$ & 0.42 & 8.3 & 0.007 & -13.5 & -2.88 & -25.0 & 0.93 & 16.8 & 0.75 & 45.6 & -12.9 & -39.4 & -1.08 & -3.98 \\
\hline $03 \times 10$ & 0.12 & 1.5 & 0.02 & -9.9 & -1.48 & -18.1 & -6.27 & -47.6 & -0.10 & -4.5 & 5.07 & -2.8 & -1.53 & -4.13 \\
\hline $04 \times 05$ & 0.31 & 7.2 & 0.13 & 46.6 & -0.69 & -9.61 & -1.29 & -7.8 & -0.15 & -15.6 & -3.03 & -5.8 & 0.18 & 2.86 \\
\hline $05 \times 08$ & -0.06 & -2.6 & -0.006 & 9.6 & -0.61 & -9.27 & -3.08 & -28.4 & 0.38 & 30 & -13.2 & -37.7 & 0.98 & 4.40 \\
\hline $05 \times 09$ & -0.14 & -5.1 & -0.02 & -12.3 & -0.49 & -4.70 & -1.86 & -17.7 & 0.16 & 4.16 & -0.30 & -8.7 & -0.23 & -2.34 \\
\hline $05 \times 10$ & 0.35 & 6.7 & 0.03 & 3.8 & -1.20 & -14.7 & -0.23 & -13.3 & 0.07 & -8.6 & 3.10 & -5.2 & -0.02 & -0.61 \\
\hline $06 \times 07$ & -0.01 & 0.8 & -0.006 & -14.6 & 1.59 & 28.13 & 3.00 & 21.8 & -0.14 & 4.42 & -7.67 & 0.74 & 0.65 & 7.75 \\
\hline $06 \times 08$ & 0.35 & 5.7 & -0.003 & 0.62 & 1.41 & 15.64 & 2.45 & 3.29 & 0.57 & 43.8 & 7.26 & 10.1 & 1.86 & 12.5 \\
\hline $06 \times 09$ & -0.32 & -10.8 & -0.02 & -20.4 & -1.92 & -10.0 & 0.18 & -7.4 & 0.05 & -0.95 & -9.07 & -24.1 & -0.45 & 2.01 \\
\hline $06 \times 10$ & -0.32 & -9.9 & -0.04 & -24.1 & -0.57 & -3.45 & -2.11 & -25.4 & -0.40 & -29.6 & -8.91 & -28.3 & -1.87 & -0.80 \\
\hline $07 \times 08$ & -0.25 & -7.4 & 0.005 & 2.5 & -2.65 & -17.2 & -0.90 & -3.4 & -0.05 & 14.3 & 0.93 & 17.6 & -2.25 & -4.77 \\
\hline $07 \times 09$ & -0.12 & -5.3 & -0.02 & -20.7 & 3.58 & 45.74 & -2.63 & -11 & -0.50 & -22 & 0.23 & 22.5 & 0.52 & -0.31 \\
\hline $07 \times 10$ & 0.47 & 9.3 & 0.006 & -11.7 & 0.88 & 13.22 & 2.45 & 18.6 & 0.59 & 17.4 & 12.4 & 51.9 & -0.04 & -0.73 \\
\hline $08 \times 09$ & -0.12 & -8.2 & 0.005 & 3.8 & 0.50 & 7.00 & -0.67 & -12.1 & -0.30 & -14 & 12.6 & 21.4 & -1.0 & -3.68 \\
\hline $08 \times 10$ & -0.38 & -13.1 & -0.05 & 3.8 & -0.83 & -9.37 & -2.89 & -31.6 & -0.55 & -31.5 & -0.16 & -10.2 & 1.24 & 3.74 \\
\hline $09 \times 10$ & -0.06 & -7.0 & -0.002 & -13.7 & 3.91 & 32.17 & 0.49 & -6.3 & 0.08 & -14.4 & -6.98 & -23.5 & -0.64 & -4.68 \\
\hline $\mathrm{SD}_{\hat{s i j}}$ & 0.044 & - & 0.005 & - & 0.254 & - & 0.298 & - & 0.027 & - & 0.200 & - & 0.153 & - \\
\hline $\mathrm{SD}_{\hat{s} i j-\hat{s} i k}$ & 0.064 & - & 0.007 & - & 0.375 & - & 0.438 & - & 0.040 & - & 0.294 & - & 0.224 & - \\
\hline $\mathrm{SD}_{\hat{s} i j-\hat{s} i l}$ & 0.061 & - & 0.007 & - & 0.358 & - & 0.418 & - & 0.038 & - & 0.280 & - & 0.214 & - \\
\hline
\end{tabular}

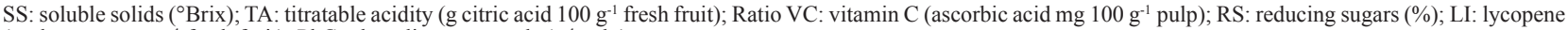
( $\mu \mathrm{g}$ lycopene $\mu \mathrm{g} \mathrm{g}^{-1}$ fresh fruit); PhC: phenolic compounds $\left(\mathrm{g}^{-1} \mathrm{pulp}\right)$ 
The search for high heterosis in tomato breeding is constant (Melo et al. 2009, Santos et al. 2011). The most heterotic hybrids tend to result mostly from crosses of genetically distant parents, increasing the chance of complementarity and allelic heterozygosity in the cross. Estimates of specific combining ability of a parent with itself $\left(\hat{s}_{i j}\right)$ provide information on the nature of dominance deviations and also on the degree of genetic divergence between the parents. Therefore, the greater the $\hat{s}_{i j}$ estimate in absolute values, the greater the genetic diversity of the parent in question in relation to the others for the loci involved in the control of the trait in question. If the estimate is negative, positive dominance effects tend to prevail, increasing heterosis (Cruz et al. 2012).

The most divergent parents for SS content were RVTD09, RVTD-08 and RVTD-10, with highest $\hat{s}_{i j}$ estimates for SS content, despite the positive sign (Table 3 ). The positive $\hat{s}_{i j}$ values however indicate that the mean heterosis effects in the crosses in which they participate is negative, unfavorable to increase the SS content (Santos et al. 2011). On the other hand, lines RVTD-05 and RVTD-07 had negative $\hat{s}_{i j}$ estimates (Table 3), positively contributing to the expression of the highest heterosis values for SS, observed in RVTD-01 x RVTD-05 (14.9\%), RVTD-01 x RVTD-07 (14.7\%) and RVTD-02 x RVTD-07 (12.3\%) (Table 4). The heterosis values for SS obtained in this diallel are in agreement with the values found in the literature (Shende et al. 2012, Souza et al. 2012).

For TA, the parents RVTD-08 and RVTD-04 had negative and high $\hat{s}_{i j}$ estimates, positively contributing to the expression of heterosis in crosses (Table 3). The highest heterosis estimates for TA were detected in the hybrid combinations RVTD-04 x RVD-05 (46.6\%), RVTD-02 x RVTD-08 (35.2\%), and RVTD-01 x RVTD-08 (26.6\%), which had the parents RVTD-08 and RVTD-04 in common, proving the actual influence of these parents on the achievement of heterotic hybrids (Table 4).

For the SS/TA ratio, the parents RVTD-07 and RVTD-02 both had negative and high $\hat{s}_{i j}$ estimates, strongly indicating higher genetic divergence in these than in the other parents (Table 3). The hybrids RVTD-07 x RVTD-09 and RVTD-02 x RVTD-09 obtained the two highest heterosis estimates of the experiment for the ratio, exceeding the parent means by approximately $45 \%$ and $33 \%$, respectively (Table 4 ).

RVTD-02 was the parent that reconciled the highest and negative $\hat{s}_{i j}$ estimate for VC (Table 3), and is an important parent in view of the genetic divergence, significantly contributing to the increase of heterosis observed in diallel crosses for this trait. The heterosis for VC content varied widely, ranging from $-47.3 \%$ to $89.1 \%$ in hybrid combinations RVTD-03 x RVTD-10 and RVTD-02 x RVTD-03, respectively (Table 4).

Variation was large in heterosis values for RA, ranging from $-35.9 \%$ to $56.2 \%$ in the hybrid combinations RVTD-04 $x$ RVTD-10 and RVTD-03 x RVTD-07 (Table 4). The highest negative $\hat{s}_{i j}$ estimate was observed for parent RVTD-03, which contributed positively to heterosis expression in crosses in which it was parent, such as hybrid RVTD-03 x RVTD-07 with maximum heterosis for RS in the experiment (Table 3 ). On the other hand, RVTD-10 has the same magnitude of $\hat{\mathrm{s}}_{\mathrm{ii}}$ as RVTD-03 for RS, but with a positive sign (Table 3), indicating high divergence of this from the other parents, but with negative dominance effects, contributing to the occurrence of negative heterosis (Table 4).

Regarding the LI fruit content, the combination RVTD-07 x RVTD-10 exceeded the parental mean by $51.9 \%$, which was the maximum heterosis observed for this trait (Table $3)$. Note that much of this heterosis results from the genetic divergence of parent RVTD-07, which had a negative $\hat{s}_{i j}$ estimate with greater magnitude (Table 3 ), indicating a strong contribution of this parent to positive heterosis values. The parent with greatest genetic divergence of the diallel for $\mathrm{PhC}$ was RVTD-06, indicating that this is a possible parent that will contribute to the occurrence of positive heterosis, as verified in the hybrid combination RVTD-05 x RVTD06 , with highest experimental heterosis (17.2\%) (Table 4).

Therefore, we concluded that the lines evaluated in diallel can be exploited in breeding programs targeting superior tomato hybrids for traits related to fruit quality for industrial processing. The non-additive effects were prevalent in the genetic control of all traits. The lines RVTD-04, RVTD-10 and RVTD-08 stood out for the presence of favorable alleles for most traits. High genetic divergence between the parents was observed for fruit-quality related traits, contributing to significant heterosis values.

\section{ACKNOWLEDGEMENTS}

The authors are indebted to the Brazilian Federal Agency for Support and Evaluation of Graduate Education (CAPES), Brazilian Council for Scientific and Technological Development (CNPq) and the center for vegetable research (NUPH) for research support and help with the experiment. 


\section{REFERENCES}

Amaral Júnior AT, Casali VW, Cruz CD and Finger FL (1999) Inferências genéticas na produção e qualidade do tomateiro sob cruzamento dialélico. Pesquisa Agropecuária Brasileira 34: 1407-1416.

Amaral Júnior AT, Casali VWD, Cruz CD, Finger LF and Scapim CA (1997) Melhoramento do tomateiro: II. Procedimento de Gardner e Eberhart na análise heterótica de características morfoagronômicas e da qualidade dos frutos. Bragantia 56: 33-44.

Benassi MT and Antunes AJ (1988) A comparison of methaphosphoric and oxalic acids as extractant solutions for the determination of vitamin $\mathrm{C}$ in selected vegetables. Brazilian Archives of Biology and Technology 31: 507-513.

Boiteux LS, Fonseca MEN, Giordano LB and Melo PCT (2012) Melhoramento genético. In Clemente FMVT and Boiteux LS (Ed) Produção de tomate para processamento industrial. Embrapa, Brasília, p. 17-27.

Brasil, Ministério da Saúde, Agência Nacional de Vigilância Sanitária, IAL Instituto Adolfo Lutz (2008) Métodos físico-químicos para análise de alimentos. Ministério da Saúde, Brasília, 1020p.

Cruz CD (2013) GENES - a software package for analysis in experimental statistics and quantitative genetics. Acta Scientiarum Agronomy 35: $271-276$.

Cruz CD, Regazzi AJ and Carneiro PCS (2012) Modelos biométricos aplicados ao melhoramento genético. Editora UFV, Viçosa, 514p.

Dhaliwal MS, Singh S, Badhan BS and Cheema DS (1999) Diallel analysis for total soluble solids cotent, pericarp thickness and locule number in tomato. Indian Society of Vegetable Science 26: 20-22.

Garg N, Cheema DS and Dhatt AS (2008) Genetics of yield, quality and shelf life characteristics in tomato under normal and late planting conditions. Euphytica 159: 275-288.
Gomes FP (1990) Curso de estatística experimental. Nobel, Piracicaba, $468 \mathrm{p}$.

Griffing B (1956) A generalized treatment of the use of diallel crosses in quantitative inheritance. Heredity 10: 31-50.

IBGE (2013) Instituto Brasileiro de Geografia e Estatística. Levantamento Sistemático da Produção Agrícola 26: 1-83.

Maluf WR (2001) Heterose e emprego de híbridos $F_{1}$ em hortaliças. In Nass LL, Valois ACC, Melo IS and Valadares MC (Eds) Recursos genéticos e melhoramento - plantas. Editora Fundação MT, Rondonólis, p. 327-356.

Melo PCT, Melo AMT and Boiteux LS (2009) Overview and perspectives of tomato breeding for fresh market adapted to mild tropical climates of Brazil. Acta Horticulturae 821: 55-62.

Rodrigues Amaya DA (2001) Guide to carotenoids analysis in food. International Life, Washington, 64p.

Saleem MY, Asghar M, Iqbal Q, Rahman AU and Akram M (2013) Diallel analysis of yield and some yield components in tomato (Solanum lycopersicum L.). Pakystan Journal of Botany 45: 1247-1250.

Santos FFB, Ribeiro A, Siqueira WJ and Melo AMT (2011) Desempenho agronômico de híbridos $\mathrm{F}_{1}$ de tomate de mesa. Horticultura Brasileira 29: 304-310.

Shende VD, Seth T, Mukherjee S and Chattopadhyay A (2012) Breeding tomato (Solanum lycopersicum L.) for higher productivity and better processing qualities. SABRAO Journal of Breeding and Genetics 44: 302-321.

Souza LM, Paterniani MEAGZ, Melo PCT and Melo AMT (2012) Diallel cross among fresh market tomato inbreeding lines. Horticultura Brasileira 30: 246-251.

Vencovsky R and Barriga P (1992) Genética biométrica no fitomelhoramento. Revista Brasileira de Genética, Ribeirão Preto, 496p. 